\title{
ARQUITETURA DE TERRA - PROCESSO HISTÓRICO
}

Amanda de Jesus Fernandes Portella, Bruna Delicolli Silva, Maria Eunice Carvalho Toselho, Rebeca Delatore Simões

Universidade do Oeste Paulista - UNOESTE, Curso de Arquitetura e Urbanismo, Presidente Prudente, SP. E-mail: amanda.portella@outlook.com

\section{RESUMO}

A construção civil tal como existe atualmente tem desequilibrado o meio ambiente. Como alternativa aos métodos modernos o presente projeto de extensão em nível de graduação objetiva resgatar o uso da terra crua como matéria prima para a construção civil através do estudo histórico desta prática considerando os conhecimentos acumulados no decorrer dos séculos em diversos continentes. A metodologia empregada consistiu no levantamento das bibliografias, artigos e pesquisas existentes sobre o assunto, cadastrando o local, as datas e as diferentes alternativas encontradas. Os dados e informações coletados foram organizados neste trabalho e ficarão disponíveis como embasamento histórico para futuras pesquisas científicas que contribuam para uma construção sustentável.

Palavras-chave: terra crua, construção sustentável, arquitetura de terra, histórico.

\section{EARTH ARCHITECTURE - HISTORICAL PROCESS}

\begin{abstract}
A construction as presently exists has unbalanced the environment. As an alternative to modern methods this extension project-level objective graduation rescue the use of raw land as raw material for the construction through the historical study of this practice considering the knowledge accumulated over the centuries in different continents. The methodology consisted of the survey of bibliographies, articles and existing research on the subject, registering the location, the dates and the different alternatives found. The data and information collected were organized in this work and will be available as a historical basis for future scientific research that contributes to sustainable construction.
\end{abstract}

Keywords: raw land, sustainable construction, land architecture, history. 


\section{INTRODUÇÃO}

Atualmente, uma das maiores preocupações que permeiam as instituições de ensino e pesquisa envolvem a sustentabilidade. Já estamos vivendo em uma época afetada pela ausência do controle no consumo dos recursos naturais fato este que requer imediata atenção e ação para um direcionamento ao desenvolvimento sustentável que abranja as dimensões econômicas, ambientais e sociais envolvendo diversas áreas do conhecimento, dentre elas a construção civil que segundo Gauzin-Muller (2002), 50\% dos recursos naturais extraídos da natureza são destinados a construir e manter em uso as edificações acrescenta-se ainda o consumo de $40 \%$ da energia produzida e $16 \%$ da água consumida para a construção e manutenção desses edifícios, que juntos são responsáveis por $25 \%$ das emissões totais de gases causadores do efeito estufa.

O olhar para o passado se faz necessário para que ocorra um avanço nas técnicas atualmente comuns na construção civil, conforme Lourenço (2002), a construção com terra é a técnica construtiva mais antiga e abrangente em nacionalidades e classes sociais. $\mathrm{O}$ estudo desses conhecimentos aliados as novas tecnologias pretendem colaborar com as preocupações ecológicas e econômicas da sociedade.

A terra como matéria-prima tem se destacado por reduzir a demanda do cimento, minimizar o transporte, possuir alta durabilidade, baixa condutibilidade térmica, dentre outras peculiaridades desta técnica. O potencial da arquitetura de terra se destaca em suas vantagens significativas em relação aos métodos construtivos atuais, já que o processo é totalmente reciclável, regula a umidade ambiental, economiza energia e diminuem a contaminação ambiental (PISANI, 2004).

Sendo assim, o presente artigo faz um relato cronológico da arquitetura de terra identificando os aspectos positivos e negativos dessa técnica construtiva, fornecendo informações históricas sobre o uso do material e as atuais ações em desenvolvimento mundialmente sobre o resgate do emprego da terra com forma sustentável de construir.

\section{Levantamento Histórico}

Segundo Minke (2011, apud PISANI, 2004) existem construções tendo terra como matériaprima desde o período pré-histórico sendo este material usado na elevação de alvenarias, de abóbodas e de outros elementos construtivos, sendo estes diferentes em cada região em suas condicionantes locais e históricas. 


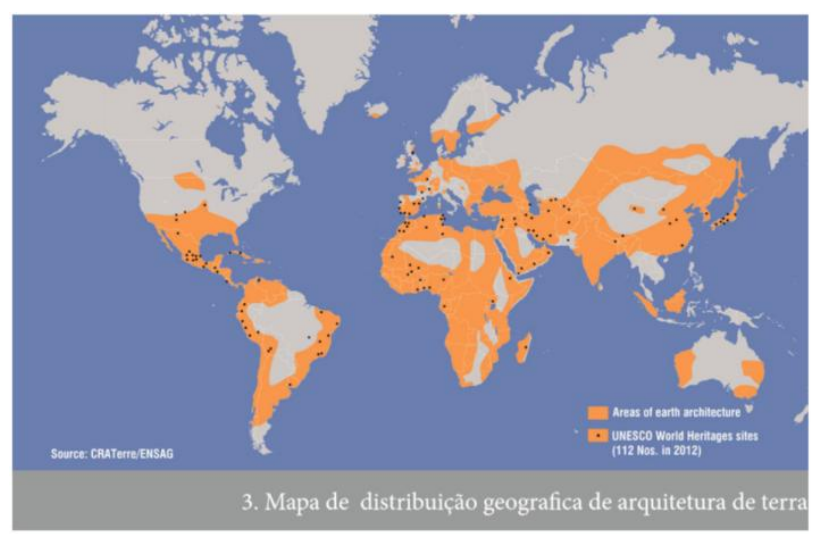

Figura 1. Mapa de distribuição geográfica de arquitetura de terra Fonte: PONTE, 2012

O potencial e a durabilidade deste material é demonstrado através dos exemplos de técnicas variadas nas mais diferentes partes do planeta, como os presentes em Jericó, China, Mesopotâmia, Irã, Iraque e em vários lugares do continente africano, cuja existência remete a cerca de 8000 anos a.C. (CARVALHO; LOPES, 2012).

Pontes (2012, p. 13) afirma que "é no Médio Oriente que nascem as primeiras civilizações arquitetônicas erguidas com o próprio solo do local, espalhando-se posteriormente para outras zonas do globo". Houben e Guillaud (1994, apud CARVALHO E LOPES, 2012) defendem que as tipologias atendidas pela técnica são armazéns, pequenas casas, fortificações, templos e até palácios.

Através de explorações realizadas em Jericó concluiu-se que esta já era uma cidade organizada no oitavo século a.C. e construída inteiramente pelos povos semitas com barro como matéria prima principal. Entre o quarto e o quinto milênio antes de Cristo esse povo já fazia uso dessas técnicas para a arquitetura templária, sendo um dos exemplos os restos encontrados em Obeid e Tel Hallaf (NONELL, 1976).

Ainda se referindo aos períodos pré-históricos, habitações de terra, datadas de 8000 a 6000 a.C., foram encontradas no Tuquestão, e a muralha da China que foi construída há 4000 anos a.C. inicialmente com uma técnica parecida com a de taipa de pilão mas posteriormente foi revestida com pedras (CARVALHO; LOPES, 2012 apud MINKE, 2001).

No Egito antigo era comum o uso de blocos de terra crua assentados com finas camadas de areia, conhecidos como adobes, para a construção desde casas até fortificações. Além do adobe, as lajes estruturadas com madeira recebiam "argamassas" que eram compostas por argila e areia para fins de preenchimento (PISANI, 2004, p.9). 
Na Europa, durante a era do bronze, principalmente nos países próximos a Alemanha, o barro era utilizado para compor muralhas e fortalezas, um dos exemplos que podem ser encontrados na atualidade é a fortaleza de Heuneberg, pertencente ao século 6 a.C.. A partir de documentos datados de 100 a.C. descobriu-se a presença de fortalezas feitas com barros também na Espanha. Na Europa central, durante os séculos 13 até 17 d.C., a terra era utilizada em conjunto com a madeira para vedações e para cobrir a palha dos telhados afim de torna-los resistentes ao fogo. Na França, um dos responsáveis pela difusão do uso da terra na construção foi o arquiteto François Cointeraux que publicou quatro folhetos sobre as técnicas nos anos 1790-1793 d.C. (MINKE, 2011, p.15).

Comentando sobre a introdução das técnicas de construção com terra na Península Ibérica, Torgal e Rute (apud PONTES, 2012 p. 15) relacionam a conquista da região pelos fenícios, cartagineses, romanos e muçulmanos com a origem, difusão e aperfeiçoamento da execução das construções com barro. "Em Portugal, principalmente na região de Algarve, é registrado o uso da taipa desde a presença romana" (PISANI, 2004, p.9)

Na cultura pré-colombiana nas Américas do Sul, Central e México existiram povos que conheciam a técnica da taipa e do adobe. Construído entre os anos de 300 e 900 d.C., foram encontradas no interior da pirâmide do Sol, em Teotihuacán, México, cerca de 2 milhões de toneladas de terra socada (MINKE, 2011).

$\mathrm{Na}$ África, a maioria das edificações religiosas também era construída com taipa, e a escolha desse material não partia apenas da preferência por parte do construtor, mas se dava pelo clima seco e a escassez da madeira nas regiões. Com o passar dos séculos, nesse local, desenvolveram-se técnicas a partir do barro para a construção de coberturas em formato de cúpulas, essas técnicas antecederam até mesmo o uso de vigas de madeira e eram tão comuns a ponto de serem aplicadas não apenas nos palácios, mas também nas residências comuns (MINKE, 2011).

Especificamente no Brasil, a técnica foi trazida pelos colonizadores portugueses já que está comprovado que os grupos indígenas brasileiros não utilizavam técnicas construtivas baseadas em barro. Além disso, os povos africanos trazidos para o Brasil pelos portugueses tinham conhecimento e experiência nesse tipo de construção (MILANEZ,1958 apud CARVALHO;LOPES, 2012). A técnica se difundiu no país principalmente nos estados de São Paulo, Minas Gerais e Goiás, exemplos de edificações duráveis construídas com taipa incluem as casas bandeiristas paulistas que já ultrapassam três séculos, e são exemplos nacionais de durabilidade devido aos cuidados recebidos contra as intempéries. O começo do declínio da taipa origina-se na capital 
paulista em 1850, visto que ali já existiam constantes enchentes e as casas de taipas corriam o risco de desabamento, assim tomou forma o cenário para o tijolo maciço aparecer como alternativa, mas somente 100 anos depois, ele veio a se tornar uma alternativa mais rápida e menos custosa o que levou a decadência e abandono total da taipa (SCHIMIDT, 1946 apud PISANI, 2004).

Enquanto o Brasil abandonava a técnica da taipa no passado recente, nos anos 60 , surge Hassan Fathy, um arquiteto egípcio que buscava materiais alternativos e democráticos para construções em países em desenvolvimento. Em sua luta pelo retorno ao uso da terra na construção, fez escola e diversos discípulos em países como Inglaterra e EUA. Esse modelo de arquitetura, em pouco tempo, tomou uma forma de arquitetura assistencialista aos países do terceiro mundo (LOURENÇO, 2002).

Como resultado do trabalho realizado por Fathy na construção da Cidade de Nova Gourna, Pontes (2012, p.19) comenta:

"O trabalho de Hassan Fathy, na construção da Cidade de Nova Gourna no Egipto (1946), demonstra precisamente a capacidade de desenvolvimento de uma comunidade, através dos seus próprios recursos. Fathy procurou trazer de volta as técnicas construtivas adicionais, trabalhando para e com a população, criando riqueza e autossuficiência, um projeto para uma cidade construída em terra e totalmente adaptada às características do local."

Sobre a oficialidade das técnicas construtivas com terra, a Alemanha foi uma das pioneiras, quando em 1951 oficializou as normas que já haviam sido criadas em 1944 pelo Earth Building Code, essa oficialização só ocorreu, pois o país sofria com a escassez de materiais construtivos póssegunda-guerra-mundial e precisava de outras opções. Mais tarde a França também oficializa algumas normas e contribuiu para a criação do CRATerre, em 1979. Atualmente, países como Nova Zelândia, Peru, Austrália e EUA possuem normas oficiais enquanto Espanha, Marrocos e Zimbábue apresentam algumas especificações sobre este tipo de construção (HOUBEN; GUILLAUD, 1994, apud PONTES, 2012, p. 26-27).

Décadas após, em 1985, o arquiteto Jean Dethier, após vários anos de trabalho no Norte da África, inaugurou um bairro experimental em L'Isle d'Abeau, perto de Lyon, França, para "demonstrar a viabilidade técnica, econômica e sócio-cultural" da arquitetura de terra. Antes dessa inauguração, Dethier foi um dos que levaram a formação do grupo CRATerre, grupo este que criou o primeiro ensino especializado em uma Universidade, em 1981 (LOURENÇO, 2002). 


\section{DISCUSSÃO}

Há mais de trinta anos o solo-cimento vem sendo apresentado como uma proposta alternativa para a construção habitacional. Todavia, é reconhecida por um pequeno grupo de técnicos e população. O surgimento da normatização e a preocupação ecológica resgataram a construção em terra em diversos países inclusive no Brasil. Isso levou ao surgimento de tijolos e painéis com terra, agregados e aditivos das mais variadas fontes e há um amplo e intrigado campo de pesquisa para ser explorado. Alguns exemplos que podemos destacar são os adobes de resíduo de sílica, de dinheiro triturado, de bagaço de cana-de-açúcar e de resíduos de construção (NEVES, 2005).

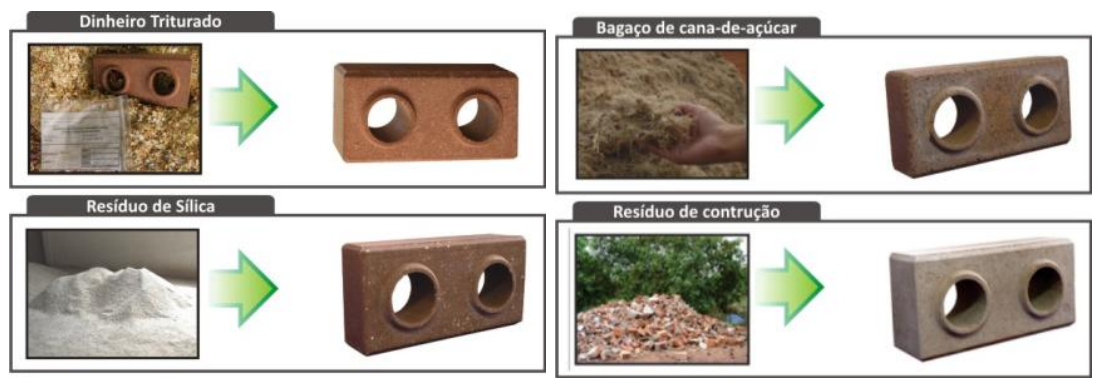

Figura 2. Variedade de composição

Fonte: Eco Máquinas ind. Comp. Imp. E Exp. Ltda

As contribuições vem de diversas partes do mundo sempre adaptadas ao clima do local, ao solo e cultura regional. O renomado escritório de arquitetura Herzog \& Meuron construiu o Ricola's herb center em Laufen, Suíça, com painéis de terra batida confeccionados com solo, cal e tufo vulcânico.

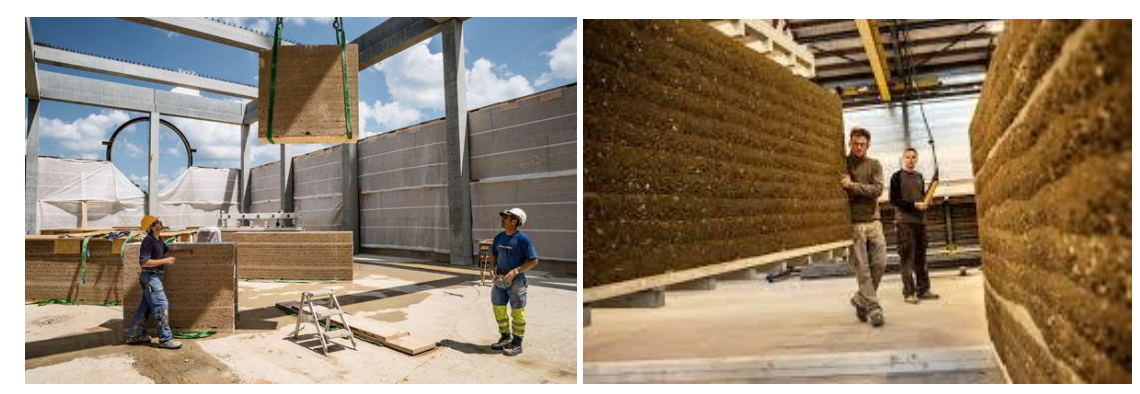

Figura 3. Herzog \& Meuron Shapes a Processing Plant with Rammed Earth.

Fonte: www.architectmagazine.com/.../herzog-de-meuron-s.Acesso em abr 2015.

Nota: Na cidade de Laufen, Suíça. 
Segundo Lourenço (2002) e Pisani (2004) essa técnica alternativa de construção possui menor impacto ambiental, as suas qualidades visto que o processo é totalmente reciclável e reutilizável, a matéria- prima é abundante, o sistema de construção é econômico, por não ser tóxico, ser incombustível, regular a umidade ambiental, possuir excelente desempenho térmico e grande durabilidade. Embora apresente algumas limitações para a sua utilização como a falta de padronização, ser permeável, sofrer deformações significativas na secagem, ter fraca resistência quando submetido à água e apresentar limitações no desenvolvimento de alturas.

\section{CONCLUSÃO}

A partir dos dados históricos coletados, concluiu-se que o uso da terra como matéria prima para construções sempre foi uma solução adotada por vários povos e sua conservação e durabilidade persistiram por milênios. A disponibilidade desse material, a facilidade de acesso e o baixo custo foram os principais motivos apontados para a sua popularidade e aceitação durante muitos séculos.

Sendo assim, essa técnica utilizada no passado, aliada as inovações e adequações regionais, ao baixo custo, a simplicidade de fabricação e a eficácia comprovada em estudos recentes, podem ser usadas na construção civil e colaborar para o surgimento de uma arquitetura sustentável.

\section{REFERÊNCIAS}

ALMEIDA, J.R. Planejamento Ambiental. Rio de Janeiro, 1993.

ARQUITETURA DE TERRA CRUA. Direção: Laura Martirani. Roteiro: Arnaldo Nolasco e Laura Martirani. IPTVUSP. 2007.

Arquitetura da terra. Acessado em 14 mar 2015. Disponível em:

<http://www.arq.ufsc.br/arq5661/trabalhos_2004-1/arq_terra/futuro.html.

Entrevista com o arquiteto Paul Oliver. Acessado em 28 fev 2015. Disponível em:

<http://www.vitruvius.com.br/revistas/read/entrevista/09.035/3285?page=1

CASTELNOU, A. M. N. Desenvolvimento e meio ambiente no 7. Sentindo o espaço arquitetônico. P. 145-154. Editora UFPR. 2003.

GAUZIN-MÜLLER, D. Arquitectura ecológica. Barcelona: Gustavo Gili, 2002.

CARVALHO, T. M. P.; LOPES, W. G. R. A arquitetura de terra e o desenvolvimento sustentável na construção civil. VII CONNEPI Palmas, TO. 2012.

CEPED.Centro de Pesquisa e Desenvolvimento. Desenvolvido por Antônio Edésio Jungles disponível em: < http://www.ceped.ufsc.br/>. Acesso em 29 abril. 2015. 
CORREIA, M., Universalidade e diversidade da arquitetura de terra. 10a Mesa redonda de Primavera. Terra: forma de construir, arquitetura, antropologia, arqueologia. Portugal,2006.

CRATERRE.ORG. Centre International de La Construction em terre. Desenvolvido por Maxime Chavagne e Florie Séchaux disponível em: < http://craterre.org/>. Acesso em 29 abril. 2015.

LOURENÇO, P. Arquitetura de Terra: uma visão de futuro. 2002.

MINKE, G. Manual de construccion em tierra. Editora Fin del Siglo, 2011.

NEVES,C. O Uso do Solo- cimento em Edificações. A Experiência do CEPED. V SIACOT- Seminário Ibero- Americano de Construção (2005). Acessado em 10 abr 2015. Disponível em http://www.cricyt.edu.ar/secprensa/siacot/cdenlinea/ponencias/comision4/Neves,\%20Celia/POCelia\%20Neves.pdf

NONELL, J.B., História da arquitectura. Editora Técnicos Associados, Barcelona, Espanha. 1976. PISANI, M. A. J. Taipas: a arquitetura de terra. Sinergia, São Paulo, v.5. 2004.

PISANI, M. A. J. Um material de construção de baixo impacto ambiental: o tijolo de solocimento. Ae ensaios. Disponível em:< http://www. aedificandi. com. br/aedificandi, n. C3, 2002.

PONTES, M. M. C., Arquitetura de terra: um desenho para a durabilidade das construções. 2012. 316 f. Dissertação. Faculdade de ciências e tecnologias da Universidade de Coimbra. Coimbra. 